\title{
GENRE ANALYSIS: THE INTRODUCTION SECTION OF TWO LONGER TEXTS ${ }^{1}$
}

Maria Lucia Vasconcellos

\section{Initial remarks}

Do introductions have a predictable structure? If they do, what is the rationale behind this organization? How is it patterned? In what ways is this pattern signaled on the surface linguistic features?

With these questions in mind, I set out to examine the introduction section of two classic works in Translation Studies (Toury, 1980 and House, 1977) to investigate their structure, the rationale behind their organization, as well as their communicative purpose and linguistic nature. For this investigation, a theoretical framework was needed within which to discuss the notion of genre and to describe the so called generic quality of introductions. Swales's work on Genre Analysis (1990), particularly his revised Create a Research Space (CARS) model, provided such a background, chosen for its capacity to capture a number of characteristics of research article introductions. In addition, as Genre Analysis is here related to Text Analysis, other theoretical frameworks incorporating textual considerations were drawn upon, particularly those describing patterns of organization in texts based on the concept

\begin{tabular}{|l|l|l|l|l|}
\hline Ilha do Desterro & Florianópolis & $n^{\circ} 39$ & p.187-201 & jul./dez. 2000 \\
\hline
\end{tabular}


of Clause Relations (Winter, 1977; Hoey, 1983 and Winter and Hoey, 1986). A summary of the main claims of these frameworks is presented in the next section.

\section{The composite framework informing this paper}

\subsection{Swales's concept of Genre}

In opposition to traditional views, which associate the concept of genre with an exclusive concern with spoken and written substance of discourse, Swales (1990) proposes a dissociation of such a link, suggesting instead a multi-layered textual approach able to account for variation in communicative purpose, addresser-addressee relationships and genre conventions. He suggests "viewing genre as rather more than texts (...) drawing extra-textual territory into genre analysis" (ibid: 6-7). In order to handle these additional dimensions, he adopts three key concepts which interlock with one another to account for the notion of genre: the notion of discourse community, the concept of genre itself and also that of task.

Unlike speech communities, which are constituted by sociolinguistic grouping, discourse communities, as sociorhetorical networks, are defined by functional criteria that include "common goals, participatory mechanisms, information exchange, community specific genres, a highly specialized terminology and a high general level of expertise" (ibid: 29). The furtherance of the aims of a discourse community is made possible by the use of genres. As Swales (ibid: 9) defines them,

genres are classes of communicative events which typically possess features of stability, name recognition and so on. Genre-type of communicative events consist of texts themselves (spoken, written or a combination) plus encoding 
and decoding procedures as moderated by genre-related aspects of text-role and text-environment. (9)

A genre is then not to be equated solely with formulaic ways of constructing particular texts, but it is to be considered a class of communicative event (one in which language plays a significant and indispensable role), whose identity is determined by its communicative purposes (text-role) within the discourse community (text-environment) in which it occurs. These communicative purposes, which are recognized by the expert members of the discourse community, constitute the rationale for the genre, that is, the set of reasons on which its very existence is based. It is this rationale that shapes the schematic structure of the discourse, influences and constrains lexical and syntactic choices. To sum it up, recognition of purposes provides the rationale, which, in turn, gives rise to the constraining conventions at a given genre.

As for the concept of task (not the focus of the present study), it suffices to say it is discussed in the context of language learning activities, referring to the notion of any rhetorical action and communicative effectiveness leading to communicative outcomes. As Swales (ibid: 72) explains, "tasks are seen as having communicative outcomes, just as genres are seen as having communicative purposes and discourse communities communicative goals."

\subsection{The Clause-Relational approach}

As mentioned above, this study was carried out within a composite framework, also including theoretical perspectives taking into account patterns of organization in texts. Among these, the clause-relational approach proposed by Winter and Hoey (Winter, 1977; Hoey, 1983 and Winter and Hoey, 1986) is drawn upon. Starting from the recognition of the interactive nature of written discourse, they claim that there are "categorizable ways in which we process or produce sentences" (23) and that the inferential connections in texts are far from random but are 
set up by writers and made by readers. These connections, both as a cognitive process and as its linguistically related product, enable the reader to interpret or the writer to create the meaning of a clause or sentence not as a separate entity but in the light of other clauses or sentences in the discourse.

One important consequence of the clause relational approach is that the lexical and grammatical choices in the text are tied inextricably to the semantic relations holding between sentences, as Hoey and Winter point out (1986: 125). That is, the decision about what relations to express affects the structuring and sequential ordering of the clauses and also the choice of the linguistic signals of various kinds expressing the clause relations explicitly. Clause relations may, in combination, form more extensive patterns of discourse organization. Among these rhetorical patterns, one proved particularly important in the textual studies carried out here: the "Problem-Solution" pattern. In simple terms, the basic components of the Problem-Solution pattern are: Situation, Aspect of Situation Requiring Response (the problem), Response to Problem and Evaluation and/or Result of Response. In other words, a Situation is introduced, a Problem is described as such as a consequence of the Situation, and a Solution is proposed to this Problem, which is then (optionally) followed by some kind of Evaluation of the Solution.

Introductions are sections which seem to be encapsulated Problem - Solution texts. This might be accounted for by the fact that the author needs to open space for his work (Situation) and justify it in terms of the incompleteness of previous contributions to the field (Aspect of Situation Requiring Response). Thus a 'Problem' is pointed out in the existing state of affairs, for which a 'Solution' (Response to Problem and Evaluation and/or Result of Response) is proposed by the work at issue. Because the clause relational patterning ties neatly with the way introductions are built, it was also included in the composite framework underlying the present study. 


\section{The Research Article as a genre}

In discussing the Research Article (RA), Swales (ibid: 118) argues for its generic quality, pointing out the fact that it has "its own quite separate conventions, its own processes of reasoning and its own standards of argument." He goes to say that the different sections in a RA perform different rhetorical functions, thus requiring different linguistic resources to realize those functions.

For the purposes of this study, the relevance of Swales' model lies in his discussion of the rhetorical function and movement in article introductions. In an attempt to capture the characteristics of introductions, Swales (ibid) proposes the "Create A Research Space" (CARS) model, suggesting the existence of a structure in introductions, in which a series of Moves occur in a predictable order. There are, he says, three Moves, subdivided into Steps, described as follows (ibid: 140):

Move 1 Establishing a territory

Step 1 Claiming centrality

Step 2 Making topic generalization(s)

Step 3 Reviewing items of previous research

Move 2 Establishing a niche

Step 1A Counter-claiming

Step 1B Indicating a gap

Step 1C Question-raising

Step 1D Continuing a tradition

Move 3 Occupying the niche

Step 1A Outlining Purposes

Step 1B Announcing present research

Step 2 Announcing principal findings

Step 3 Indicating RA structure 
Such a subdivision, however, does not necessarily take place in every piece of introduction, an either/or pattern many times occurring among the steps.

Swales's model was devised for introductions to research articles; in this study, however, the model is extended to introductions to longer texts, particularly books on translation studies. This application of the Move/Step analysis is justified if one considers introductions to academic work in general as partaking the same genre, that is, 'introductions to research articles, books, theses and dissertations': in this context, introductions have the same communicative purpose, which has a bearing on the conventions constraining language selection and organizational pattern.

\section{The present study: The historical context and the corpus selected}

Three concerns inform this study: (i) to check the CARS model against introductions to longer texts; (ii) to see the extent to which the Moves could be mapped onto the Problem-Solution pattern; and, (iii) to examine the linguistic realizations signaling the relations spelled out lexicogrammatically.

Work in a similar line was carried out by Dudley-Evans (1986). He investigated the introduction and discussion sections of seven Msc dissertations of foreign postgraduate students at the University of Birmingham. Drawing on Swales' previous work on genre (1981) and showing how genre analysis relates to discourse and text analysis, Dudley-Evans discussed the patterns of organization of such sections with a view to establishing a model for the teaching of dissertation writing. His results confirmed the validity of the Move analysis approach (though an extension of Swales' model was needed to account for the corpora analyzed) as well as its interconnection with the ProblemSolution patterning.

While Dudley-Evans' concern was mainly with the pedagogical implications of models of organizational patterns of academic texts, 
my concern is with textual properties and textual effectiveness as seen against the background of their relationship to the status writers hold in the context in which their work comes into life. In other words, the present research was carried out to examine the extent to which the writer's success or failure in posing his research question was linked to his ability to conduct the reader through the different Moves, especially in establishing the gap in knowledge against the background of accepted shared information.

The Introductions to two works were investigated ${ }^{2}$ :

(i) Toury, G. (1980) In search of a theory of translation. Tel Aviv: Academic Press \& The Porter Institute for Poetics and Semiotics, Tel Aviv University Press.

(ii) House, J. (1977). A model for translation quality assessment. Tubingen: Gunter Narr Verlag.

\section{Analysis of the Introductions}

This section will present a discussion of the linguistic realizations of the rhetorical movement in the introductions, in terms of Moves/ Steps and organizational patterns analyses. For easier identification, these realizations will be indicated in italics.

\subsection{Toury's Introduction: "Foreword"}

This introduction reflects Toury's preoccupation with providing the field of translation studies with what he sees as a unified framework to account for the translational phenomena in a systematic way. His claim is the need for a general translation theory, able to describe and account for every translational phenomenon occurring or capable of occurring. As he opposes his work to existing studies in translation theory, he places his perspective against the context of the general literature of the field, calling the existing theories into question. From the very opening sentence, he points out lacunas in those theoretical spaces, which makes room for the introduction of his view and his model. 
When the CARS model is applied to Toury's text, there emerges the picture described next.

Move 1 is coterminous with "discipline of translation studies". The author establishes the field by claiming centrality to his work, inviting the members of the discourse community to accept it as a contribution to a significant and well-established research area. The linguistic realizations in this move show the reader that there are, in fact, many other investigators active in the area. This can be seen in: "most of the theories that have been produced to date (...)", and in "very much work has been done". To enhance the strength of the centrality claim, Toury uses an integral quotation from an established researcher (Holmes, 1972: 12-13), with which he points to a gap in the state of the art: "Most of the theories that have been produced to date are in reality little more than a prolegomena to [...] a general translation theory $(. . .)^{\prime \prime}$. In this introduction, no clear-cut division exists between Move 1 and Move 2, as Move 2 is signaled in advance at the very core of Move 1. Move 2 can, however, be said to conflate with the adversative sentence connector but, in "(...) but, in spite of the growing number of publications on various aspects of the discipline and of its subject matter alike, the awaited general theory of translation is still very much wanted".In addition, this Move can be identified in some lexical signals of gaps, as in "awaited" and "very much wanted", with which it is coterminous.

The key signal introducing Move 3 is the expression "the present work", with which the niche established previously is occupied. This Move is coterminous with "to encourage", thus taking up nothing less then eight out of nine paragraphs of the introduction.

Toury does not seem to be under rhetorical pressure to establish the importance of his theory against the background of what has been written in his field. On the contrary, he makes minimal reference to previous work (Move 1, Step3, above) via the insertion of a couple of words carrying implications of reference to the state of the art: "very much has been done" In fact, it does not take the author more than 
three sentences to prepare the discourse community to accept that there is indeed a niche, occupied in Move 3. This rhetorical maneuver is managed by Step 1A - 'Announcing Present Research' —and Step 1B'Outlining Purposes': "the present work (...) to unify this book"; Step 3 — Indicating Structure' — completes the scene: "The book is divided into four parts".

The possible rationale for this procedure might include: (i) the author's presumed high position in the community of translation scholars; and (ii) the fact that the field is relatively new and has little accumulated research tradition, for which some lexical selections provide evidence: "the young but rapidly developing discipline".

When Toury's text is analyzed in the light of the Clause Relational approach, it is found to exhibit a pattern commonly used in introductions, namely the 'Problem-Solution' pattern. Here, the opening sentence establishes the 'Situation' and antecipates the 'Problem' by telling the reader that "most of the theories are in reality a little more than a prolegonema to a general translation theory" (this stage coinciding with Move 1 in the analysis following Swales's model). The 'Problem' is explicitly signaled by the adversative "but" as well as by the lexical items "awaited" and "very much wanted" (this stage coinciding with Move 2 in the analysis following Swales's model). These items not only indicate the Problem but also create the expectation of a Solution .

The next two paragraphs can be seen as a 'Positive Response' or 'Solution', in the perspective of the Clause Relational approach, mainly for two reasons: (i) their position in the whole 'Problem-Solution' pattern and (ii) the presence of typical signals of 'solution', which provide support for this interpretation: "steps in (...) search for a such a theory" and "it has something to offer". Although there is a coincidence with Move 3 in the analysis following Swales's model, the recognition of the 'Solution' as positive implies that the pattern is complete, thus putting an end to the cycle. The implication is then that such an analysis alone cannot account for the rest of the introduction, which consists of descriptions of focus and organization of the book. However, on the 
whole, the "Problem-Solution' pattern was found to correspond to the rhetorical movements from one Move to another in the Moves analysis carried out above.

\subsection{House's Introduction: "Chapter 1"}

House's book is essentially the text of her Ph.D. dissertation, which proposes a working tool for translation quality assessment. Her perspective is that of translation criticism, a field she claims to be in want of a model for the description and assessment of translations as finished products. Thus, her rhetorical work in this Introduction is concentrated in creating research space, by problematizing traditional treatments of the subject, which she is not so successful in doing.

The author's strong concern with creating a research space is apparent in the recycling quality of Move 2 ('Establishing a Niche'), which keeps recurring in the development of the introduction, as demonstrated below.

Move 1 is realized by Step 3, in which the author reviews previous research, quoting scholars in the field whose models of translation "represent considerable progress over earlier traditional treatments of the subject". The gap in the so called "earlier traditional treatments of the subject" is signalled lexically by what might be considered to be Move 2, Step 1B ('Indicating a gap'): items such as "anecdotalimpressionistic treatments" set the tone of the lacuna. The 'Solution' to this "earlier" Problem is then attributed to Kade and Nida \& Taber, scholars referred to as the "more recent attempts", mentioned in a way that could be read as positive. However, they are also criticized in expressions such as "have not proved to be of immediate usefulness" and "far too general and elusive to be of any use as criteria in the concrete evaluation of a translation". Thus, it seems that Move 1 and Move 2 ('Establishing a territory' and 'Establishing a niche')are intermingled, in a way that is far from convincing. This can be seen in the author's locating the gap (lack of a model for translation quality assessment) in a body of theoretical work which, according to evidence provided by the Introduction, does not claim to have such a purpose: 
the author herself acknowledges, in the opening sentences, the fact that those were attempts to "describe and explain the process of translation".

Other instances of gap indication attest to the recycling character of Move 2: even inside Move 3, where one would assume the territory to be established and the niche to be occupied, examples of gap indication are to be found: "(...) no explicit practical guidelines for a coherent analysis and evaluation of a translation have been given" and "Translation has been a controversial subject in discussions of FLT methodology for a long time".

A similar situation occurs even in Step 3 of this final Move, where an indication of the organization of the study would typically be expected: here lexical realizations of 'Problem' are evidence of the recycling quality of Move 2, as can be seen in "(...) the insufficiency of previous attempts". This feature of House's Introduction makes it difficult to separate Move 2 from Move 3. The latter is clearly coterminous with "foreign language teaching", lexical realizations which close the Introduction. As for the former, no boundaries can be determined.

The same mingled quality is noticed when this Introduction is looked at from the perspective of Winter's organizational patterns.

The first two sentences present what is to be understood as the 'Situation': Kade's and Nida \& Taber's models of translation are offered as the state of the art and are presented as 'Solution' to previous 'Problem', which is signaled in items such as "considerable progress over earlier treatments", which were presented as "impressionistic and anecdotal". However, the 'Evaluation' of the 'Solution' they represent is negative, as "they have not proved to be of immediate usefulness" and are described in the same terms: "impressionistic and vague". Thus, the cycle is not closed, since the 'Problem' remains. The 'Situation' cannot be clearly separated, as it seems to be coterminous with "to be of any use as criteria in the concrete evaluation of a translation", which is the expression of a gap, the 'Problem'. In other words, the 'Situation' is presented both as 'Solution' and as the 'Problem' itself. 
The beginning of the second paragraph, however, signals what is supposed to be the explicitation of the 'Problem': "As yet, no explicit practical guidelines for a coherent analysis and evaluation of a translation have been given". The interesting point here is that the author is forcing the establishment of the 'Problem' in a territory where the existence of the issue is not even at stake. That is, neither theory cited in the 'Situation' claims to offer models of 'assessment'. They are models of 'translation', which, as pointed out above, seek to describe and explain the process of translation. Thus, they cannot be committed with solving a 'Problem' that is not even considered as pertaining to their main pursuits.

This description suggests that the preparation of the discourse community to accept the fact that there is indeed a 'Problem' - to be solved by the study in question, which would "bring some clarification into the field of translation quality assessment" - is not convincing enough.

The question remains as to the extent to which the movements in the 'Problem-Solution' pattern coincide with the signals of change along the Moves in the in the analysis following Swales's model.

However mingled, Move 1, Move 2 and Move 3 can be mapped onto 'Situation/Problem' and 'Solution': in both contexts, these instances are recognizable (though not separable in their internal make-up) and seem to coincide. Special attention is to be given to Move 3, which can be equated with the 'Solution': it has Step 1 ('Outlining purposes') as its obligatory element; this Step is, however, signaled twice and in two different ways, as follows; "It is the purpose of this study (...) to develop an eclectic translation quality assessment model"; and "we aim to outline some alternative ways of using translation (...) in developing students' communicative competence". This twofold quality of the 'Solution', which point to two different kinds of 'Problem' not clearly dealt with, might be an explanation for the confusing and ineffective character of House's Introduction. In addition, it might as well provide evidence to the claim made above, that the success of the introduction 
is linked to its writer's ability to conduct the reader through the different moves and relations, as well to the efforts towards opening a research space in the discourse community of which he/she claims to be a part.

\section{Results and Discussion}

The analysis carried out here confirms the generic quality of introductions in the sense that the two texts examined were found to have a pattern of organization, both typical and predictable. Although generalizations cannot be drawn from the study of only two texts, this configuration points to an affirmative answer to the first question posed at the beginning of this paper. A Move-analysis approach associated with the Clause Relational perspective was found to be fruitful, confirming previous research.

The second question, that concerning the rationale behind the rhetorical structure, can be answered with recourse to the definition of a genre here adopted: the identity of a genre is determined by its communicative purposes within the discourse community in which it occurs. Following this line of thought, it can be said that the purposes recognized by the members of the academic world (the discourse community at issue) include, among other considerations, the need to establish the significance of the research field itself and the need to situate the actual research against the background of work developed within this same community. This placing of the work in the context of the general literature of the field and this justification of the present work via the demonstration of gaps in previous research thus constitute the underlying motives shaping the discourse structure and influencing the rhetorical maneuvers carried out. This rationale has a bearing both upon the lexical and the syntactical choices, affecting the organizational pattern in introductions, the linguistic features functioning as explicit signals of the rhetorical movements.

In addition, the analysis carried out here is suggestive of the relationship holding between the need to establish a research space in 
the eyes on the academic community and the degree of adherence to the typical rhetorical movement in introductions. In this sense, two facts cannot be overlooked: (i) the association between the different rhetorical movements in the two introductions and the place occupied by the two authors in the community of translation studies and, (ii) the fact that House's Introduction is part of her Ph.D. work, a feature which, alone, might account for her greater rhetorical efforts and rhetorical instability in the development of her texts. This statement is, however, in need of further research to be properly validated, a more extensive corpora obviously having to be examined.

\section{Notes}

1 This is a revised version of a paper written under the supervision of Dr José Luiz Meurer as part of the requirements of the discipline "Text Analysis", taught at the 'Programa de Pós-Graduação em Inglês' - PGI, Universidade Federal de Santa Catarina, UFSC/ SC, 1993.

2 The reader is invited to read the introductions before the analysis; these are provided in the Appendix

\section{Bibliography}

Dudley-Evans, T. “Genre Analysis: an investigation of the introduction and discussion sections of Msc dissertations". In Coulthard, M. (Ed.) Talking about text. Birmingham, UK: English Language Research, Birmingham University, 1986.

Hoey, M. On the surface of discourse. London: George Allen and Unwin, 1983.

Hoey, M. and E. O. Winter. "Clause relations and the writer's communicative purpose". Couture, B. (Ed.) Functional approaches to writing. Ablex Pub and Frances Pinter, 1986. 
House, J. A Model for Translation Quality Assessment. Tubingen: Gunter Narr Verlag, 1977.

Swales, J. Genre analysis. English in academic and research settings Cambridge: CUP, 1990.

Toury, G. In Search of a Theory of Translation. Tel Aviv: Academic Press \& The Porter Institute for Poetics and Semiotics, Tel Aviv University Press, 1980.

Winter, E. O. "Aclause-relational approach to English texts: a study of some predictive lexical items in written discourse". In Instructional Science vol. 6, (1977) 1-92.

Winter, E. O. "Clause relations as information structure: two basic text structures". In Coulthard, M. (Ed.) Talking about text. Discourse Analysis Monograph 13, 88108, University of Birmingham, 1986. 